\title{
Effect of Blended Ionomers on the Strain Hardening of Polyester-Type Elastomer/Ionomer Blends
}

\author{
By Akihiro NISHIOKA, ${ }^{1, *}$ Satoshi ONODERA, ${ }^{2}$ Tomonori KODA,${ }^{2}$ Ken MIYATA,${ }^{2}$ \\ Kenji FURUICHI, ${ }^{3}$ Katsuhiro KODAMA ${ }^{3}$ and Kiyohito KOYAMA ${ }^{2}$
}

A Na-type ionomer based on poly(ethylene-co-methacrylic acid) (EMAA-Na ionomer) was blended with thermoplastic polyester elastomer (TPEE) and the effect on uniaxial elongational viscosity was investigated. To clarify the effect of the degree of neutralization (ND) by the EMAA-Na ionomer on strain hardening of TPEE/ionomer blends system, EMAA-Na ionomers with different NDs were prepared and blended with TPEE above their melting temperature using a twin screw extruder. An unexpected strong strain hardening was observed for a ND above $40 \%$ for a TPEE/EMAA-Na blend ratio of 80 / $20 \mathrm{wt} \%$, which corresponds to the critical ND for the formation of ion aggregates. The results can be explained using the acid-cation exchange mechanism proposed by Vanhoorne and Register. It is considered that blending EMAA-Na ionomers is an effective method for the modification of TPEE with respect to the intensity of strain hardening under uniaxial elongation. KEY WORDS: TPEE / Ionomer / Rheology / Ion Aggregates / Uniaxial Elongation / Strain Hardening /

Ionomers are polymers that include a small amount of metal ionic salt groups. Poly(ethylene-co-methacrylic acid) (EMAA) neutralized with sodium ( $\mathrm{Na}$ ) cations is widely used in industrial applications, such as golf balls and food packaging film, etc. The structural and mechanical properties of ionomers in both the solid and melt states have been extensively investigated. Ionic groups tend to form ionic aggregates in a hydrophobic polymer matrix. ${ }^{1-5}$ Dielectric, dynamic mechanical relaxation and melt rheological studies show that the occurrence of microphase separation of ionic aggregates and the hydrocarbon matrix is dependent on the degree of neutralization (ND) of the ionomer. Hirasawa et al. and Tachino et al. suggested that for a EMAA-Na ionomer in the solid state, ionic aggregates were formed when the ND exceeded $35 \% .^{6,7}$ Nishioka et al. reported a rheological investigation for the EMAA-Na ionomer in the melt state that showed ionic aggregates are formed at a ND of approximately $40 \%{ }^{8}$ These results indicate that there is a critical ND for the formation of ion aggregates that exists between 35-40\%.

Many melt rheological studies on EMAA ionomers have been conducted; however, most of these studies were related to EMAA ionomers as a polymer matrix..$^{8-15} \mathrm{We}$ consider that research of ionomers for the modification of melt rheology should be noted for new applications. To clarify the roll of blended ionomers for the modification of melt rheological properties, especially uniaxial elongational viscosity, is an important field of research for industrial application.

Much research has already been carried out regarding the solid state application of ionomers to blend with polymer materials. ${ }^{16-18}$ However, very few studies on the melt rheological properties of ionomer blend systems have been carried out. ${ }^{10,19,30,31}$
The development of methods for the modification of melt rheological properties such as strain hardening under uniaxial elongation is of significant importance for the processability of polymer materials. Nishioka et al. have reported that intensity of strain hardening for styrene-co-methacrylic acid (StMAA) can be significantly reinforced by blending only a small amount of EMAA-Na ionomer. ${ }^{19}$ They concluded that this unexpected phenomenon of this blend system was due to strong interaction between the ionic bonding (-COO-Na) in EMAA-Na ionomers and the non-neutralized acid (-COOH) of StMAA. From this result, we consider that this concept could be applied for modification of the melt rheological properties of low melt strength materials, such as thermoplastic polyester elastomer (TPEE). Modification of viscosity such as strain hardening of low melt strength TPEE was investigated using the EMMA-Na ionomer. The purpose of this investigation is to examine the effect of the ND (with and without metal ion) of the blended EMAA-Na ionomer on strain hardening properties under uniaxial elongation of the TPEE/EMAA-Na blend system. Thus, in this study, effect of with and without ion bonding should be investigated on uniaxial elongational viscosity under linear and non-linear region for TPEE/EMAA-Na blend systems.

\section{EXPERIMENTAL}

\section{Samples}

EMAA (Mitsui-DuPont Polychemicals Co. Ltd, Japan; $\left.M_{\mathrm{n}}=19,200, M_{\mathrm{w}}=94,500\right)$ with a methacrylic acid content of $15.0 \mathrm{wt} \%(5.4 \mathrm{~mol} \%)$ was used as the ionomer base. The EMAA was partially neutralized with $\mathrm{Na}$ ions. Samples were designated as EMAA-xxNa, where $\mathrm{xx}$ indicates the ND of the ionomer.

\footnotetext{
${ }^{1}$ Cooperative Research Center (CRC), Yamagata University, Japan

${ }^{2}$ Department of Polymer Science and Engineering, Yamagata University, Japan

${ }^{3}$ Research Center, Toyobo Co., Ltd, Japan

*To whom correspondence should be addressed (Tel/Fax: +81-238-26-3207, E-mail: nishioka@yz.yamagata-u.ac.jp).
} 
Table I. Samples used in this study

\begin{tabular}{cc}
\hline Composition(abbreviation) & Neutralization Degree of EMAA-Na ionomer(\%) \\
\hline TPEE & - \\
TPEE/EMAA & 0 \\
TPEE/EMAA-20Na & 20 \\
TPEE/EMAA-40Na & 40 \\
TPEE/EMAA-54Na & 54 \\
TPEE/EMAA-80Na & 80 \\
\hline
\end{tabular}

Prior to the experiments, great attention was paid to the moisture content of the ionomers due to strongly affect on rheological properties. ${ }^{20}$ According to the studies of Nishioka et al. ${ }^{20}$ a drying condition of $80^{\circ} \mathrm{C}$ for $14 \mathrm{~d}$ was considered to be effective for the removal of water content. Prior to blending, all pellet samples were dried in a vacuum oven under these conditions. The TPEE (Trade name: PELPREN, Toyobo Co. Ltd., Japan) used in this study was a di-block type elastomer consisting of polybutylene terephthalate as the hard segment and polytetramethylene glycol as the soft segment in a 70/30 weight ratio.

To clarify the effects of the ND of EMAA-Na ionomers on the strain hardening of TPEE/EMAA-Na ionomer blend systems, EMAA-Na ionomers with different NDs were prepared. The blended samples were prepared by melt compounding above their melting temperature $T_{\mathrm{m}}$, through a counter-rotating twin-screw extruder (Technovel KZW-30; $\mathrm{L} / \mathrm{D}=45$ ) at $230{ }^{\circ} \mathrm{C}$. The weight fraction of each sample was constant at $80 \mathrm{wt} \%$ for TPEE and $20 \mathrm{wt} \%$ for the EMAA$\mathrm{Na}$ ionomer. The samples examined in this study and their ND values are listed in Table I.

\section{Measurement}

Differential scanning calorimetric (DSC; TA Instruments, Q-100) measurements were conducted on $5 \mathrm{mg}$ specimens at a heating rate of $5{ }^{\circ} \mathrm{C} / \mathrm{min}$. Uniaxial elongational viscosity measurements were conducted at $230{ }^{\circ} \mathrm{C}$ under a nitrogen atmosphere using a rotational rheometer (TA Instrument, ARES) with constant strain rates of $1.0,0.5,0.3,0.1,0.05$ and $0.01 \mathrm{~s}^{-1}$. The test fixture geometry was based on an elongational viscosity fixture (EVF) after Meissner's method. ${ }^{29}$ All rectangular shaped samples $\left(0.5 \times 7 \times 60 \mathrm{~mm}^{3}\right)$ for uniaxial elongational measurements were produced by the hot press method using a uniaxial press (Toyoseiki, Co. Ltd, Mini-Test Press-10) at $230{ }^{\circ} \mathrm{C}$ under $15 \mathrm{MPa}$ pressure. Transmission electron microscopy (TEM) observation (Nihon Denshi, JEM2010) were conducted to observe morphology of our blend system before and after elongation. Elongated samples for TEM observation were prepared by rapid quenched after uniaxial elongation. Concretely, the sample was removed from rheometer for uniaxial and then it was rapid quenched in ice water bath. The specimen was cryomicrotomed at $-60^{\circ} \mathrm{C}$ to obtain cross section of it. The ionomer domains were stained by $\mathrm{NaClO}$ solution with $\mathrm{RuO}_{4}$. The TEM microscope used in this observation was operated at $200 \mathrm{kV}$.

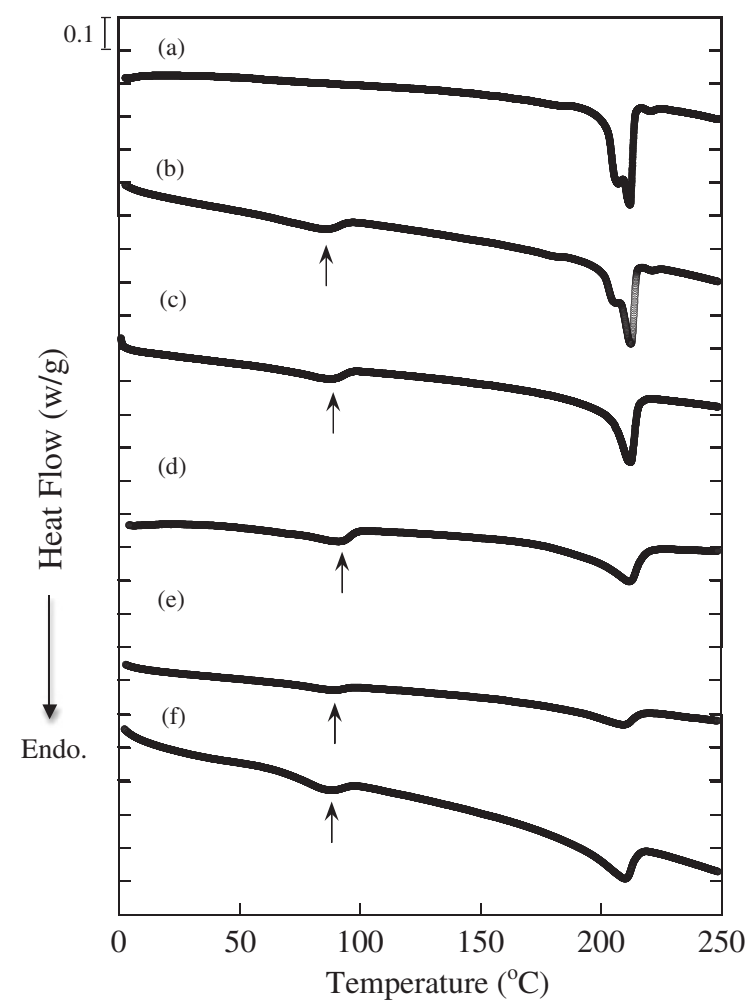

Figure 1. DSC curves for (a) TPEE, (b) TPEE/EMAA, (c) TPEE/EMAA 20Na, (d) TPEE/EMAA-40Na, (e) TPEE/EMAA-54Na, and (f) TPEE/EMAA-80Na. The weight fraction of TPEE and the EMAAionomer is $80 / 20 \mathrm{wt} \%$. The scan rate is $5{ }^{\circ} \mathrm{C} / \mathrm{min}$.

\section{RESULTS AND DISCUSSION}

Figure 1 shows DSC curves of TPEE, TPEE/EMAA and three different TPEE/EMAA-Na ionomer blends. The results of the second heating are presented. For pure TPEE, only one peak corresponding to $T_{\mathrm{m}}$ was observed around $200^{\circ} \mathrm{C}$. On the other hand, for TPEE/EMAA and TPEE/EMAA-Na ionomer blends, another peak was observed. The peak at $80^{\circ} \mathrm{C}$ corresponds to the $T_{\mathrm{m}}$ of the EMAA and EMAA-Na ionomer and the peak at $200{ }^{\circ} \mathrm{C}$ corresponds to the $T_{\mathrm{m}}$ of TPEE. The DSC results show the $T_{\mathrm{m}}$ of each component independently, which indicates that the blend systems are immiscible systems.

The results for the elongational viscosity $\eta_{\mathrm{E}}(t, \varepsilon)$ of TPEE/ EMAA-40Na, TPEE/EMAA-54Na, TPEE/EMAA-80Na ionomer blends are given in Figure 2. For TPEE, TPEE/EMAA and TPEE/EMAA-20Na, the melt viscosity was too low to obtain uniaxial elongational viscosity measurements. For this reason, the three times value of linear viscosity, $3 \eta_{\mathrm{s}}$ for TPEE, TPEE/EMAA and TPEE/EMAA-20Na are listed as solid lines in Figure 2, too. In case of high $\mathrm{ND}(\geq 40 \%)$ ionomer blended with TPEE, the uniaxial elongational viscosity could be obtained due to its high viscosity. These results allows us that by blending high ND ionomers $(>40 \%)$, the elongational viscosity at linear and non-linear region was apparently increased. This results shown in Figure 2 means that contain of metal ion and ND strongly affect on elongational viscosity 


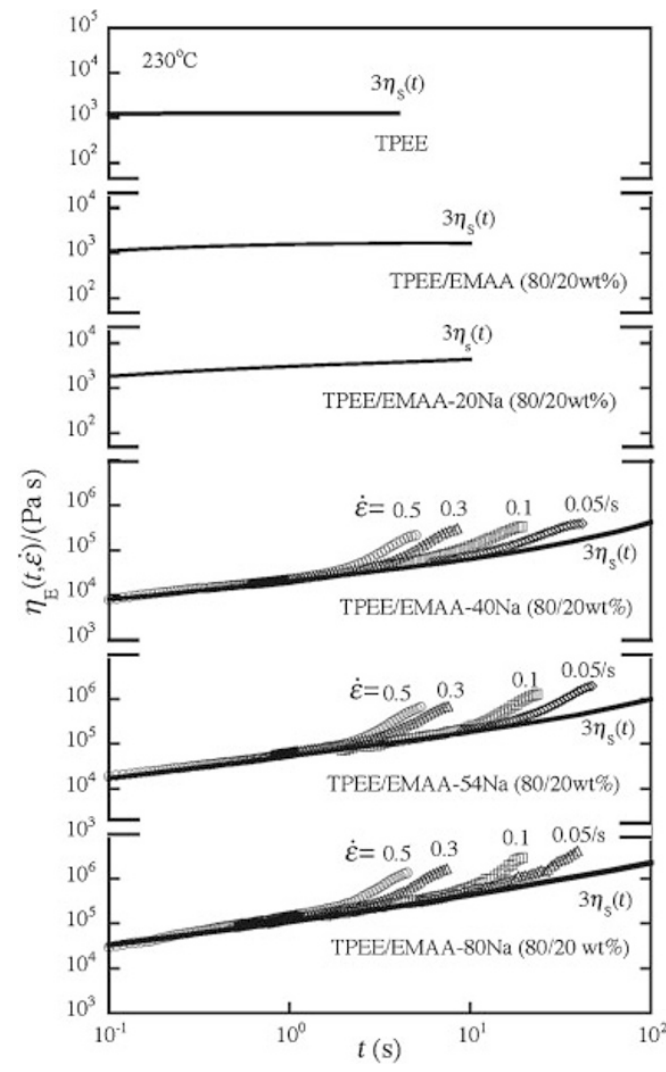

Figure 2. Uniaxial elongational viscosities for TPEE/EMAA-40Na, TPEE/ EMAA-54Na, TPEE/EMAA-80Na blends at $230^{\circ} \mathrm{C}$. All uniaxial strain rates are constant. The solid line indicates the three times value of shear viscosities $\left(3 \eta_{\mathrm{s}}(t)\right)$ for TPEE, TPEE/EMAA,TPEE/ EMAA-Na ionomer blends.

both of linear $\left(3 \eta_{\mathrm{s}}(t)\right)$ and non-linear region such as strain hardening. It should be noted that this apparent increasing of viscosity (linear and non-linear region) was observed when high $\mathrm{ND}(>40 \%)$ ionomer was blended with TPEE. The critical value of ND $40 \%$ corresponds to the critical value for the formation for ion aggregates as reported by Nishioka et al. ${ }^{8}$ It is considered that modification by blending with an ionomer is strongly correlated to the formation of ion aggregates in the EMAA-Na ionomer blend. In Figure 2, the solid line indicates the three times value of linear viscosity, $3 \eta_{\mathrm{s}}$ as mentioned above. Linear viscoelastic envelopes (LVE), which corresponds to the elongational viscosity at shorter times, were in good agreement for all blends with respect to $3 \eta_{\mathrm{s}}(t)$, as expected from the theory of linear viscoelasticity proposed by Trouton. ${ }^{21}$ At longer times, there was a significant increase of uniaxial elongational viscosity with time, which is strain hardening, observed for all the blend samples at all strain rates.

To clarify the effect of the ND of blended ionomers on the intensity of strain hardening, the non-linear parameter $\lambda \mathrm{n}$, proposed by Koyama et al., was used: ${ }^{22}$

$$
\lambda \mathrm{n}=\eta_{\text {nonlinear }} / \eta_{\text {linear }}
$$

where $\eta_{\text {linear }}$ and $\eta_{\text {nonlinear }}$ are elongational viscosity in the short and long time regions, respectively. The results of the non-linear parameter $\lambda \mathrm{n}$ calculated for the blend systems are

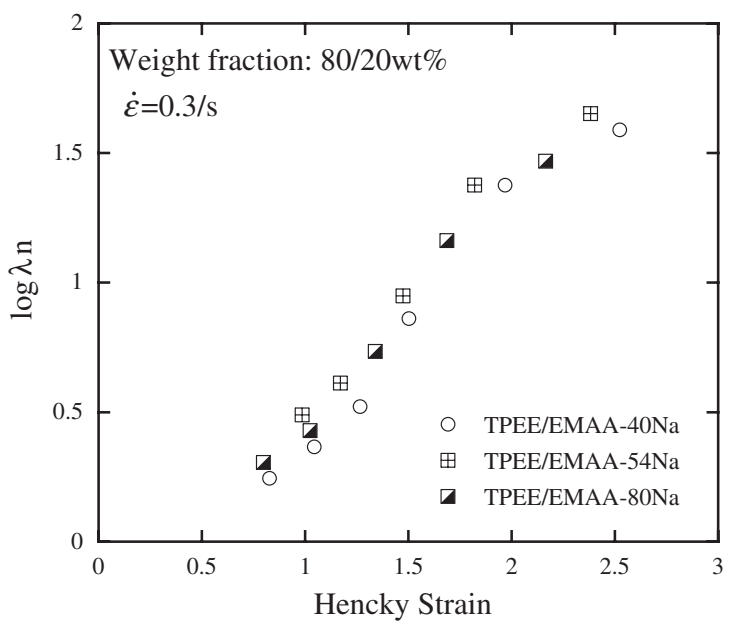

Figure 3. Non-linear parameters $(\lambda n)$ for TPEE/EMAA-Na blend systems. The constant strain rate is $0.3 \mathrm{~s}^{-1}$.

shown in Figure 3 . The degree of the slopes of $\lambda \mathrm{n}$ corresponds to the intensity of strain hardening. Figure 3 shows similar degree of the slopes and little dependence of the ND on the intensity of strain hardening. Therefore, the blending of high $\mathrm{ND}(>40 \%)$ ionomers with TPEE can apparently modify the intensity of strain hardening, although it does not depend on the ND of the ionomer. Thus, from Figure 2 and Figure 3, linear and non-linear visocosities were increased by blending high ND ionomers. These results investigate that in case of critical value of $\mathrm{ND}(>40 \%)$ for formation of ion aggregate, effect of blending ionomers on elongational viscosity was hardly changed. However, we can understand that blending high ND ionomer was apparently effective for linear and non-linear viscosity. We concluded that this phenomena can not observed in case of blending $\operatorname{EMAA}(\mathrm{ND}=0)$ and low $\mathrm{ND}$ ionomers such as EMAA-20Na.

The modified intensity of strain hardening as show in Figure 2 is unexpected, especially for immiscible blend systems. Some researchers have reported that for immiscible blend systems, the intensity of strain hardening should be decreased in comparison to the matrix polymer. Li et al. reported that in the case of immiscible blends, such as poly(methyl methacrylate) (PMMA)/polyphenylsilsesquioxane (PPSQ) blends, the intensity of strain hardening was reduced from that of the matrix polymer. ${ }^{23,24}$ They concluded that the reduction in strain hardening was due to hard PPSQ particles that were not deformed during elongation.

The deformation of domains during elongation has a significant affect on the intensity of strain hardening. In the present case, significant strain hardening was observed in immiscible TPEE/ionomer blends. These unexpected results should be discussed with respect to the morphology of domain deformation.

In order to confirm dispersed morphology of EMAA-Na ionomers into the TPEE matrix before and after elongation, TEM observation was performed. Figure 4 shows TEM images of the blend systems before elongation. Clear island regions 


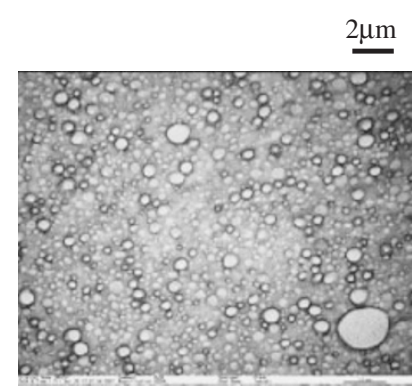

(a) TPEE/EMAA $(80 / 20 \mathrm{wt} \%)$

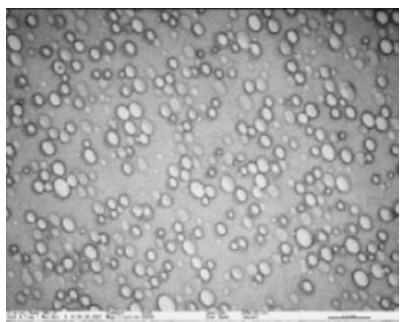

(c) TPEE/EMAA-40Na (80/20 wt $\%)$

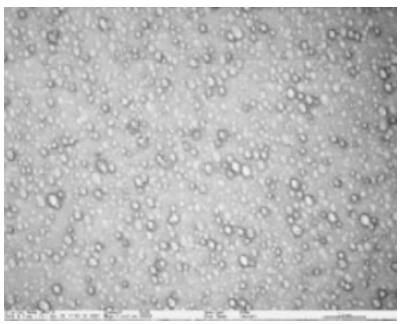

(e) TPEE/EMAA- $80 \mathrm{Na}(80 / 20 \mathrm{wt} \%)$

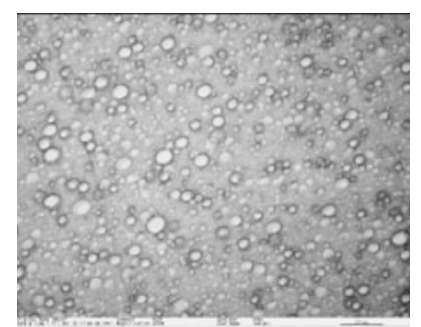

(b) TPEE/EMAA-20Na (80/20 wt $\%)$

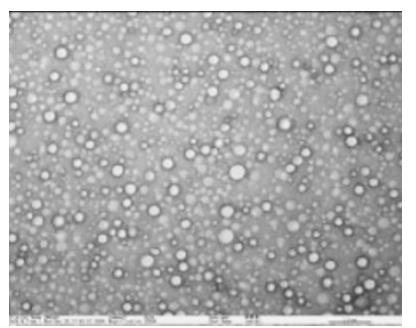

(d) TPEE/EMAA-54Na $(80 / 20 \mathrm{wt} \%)$
Figure 4. TEM images of (a) TPEE/EMAA, (b) TPEE/EMAA-20Na, (c) TPEE/EMAA-40Na, (d) TPEE/EMAA-54Na, and (e) TPEE/ EMAA-80Na blends. The TPEE/EMAA blend ratio is $80 / 20 \mathrm{wt} \%$. White particles indicate domains of EMAA and its ionomers.

indicate dispersed EMAA and EMAA-Na ionomer domains. The average diameter of domains before elongation was calculated and is shown in Figure 5. The average diameter of domains was decreased with increasing ND of the EMAA-Na ionomer, which indicates that the miscibility between TPEE and EMAA-Na ionomers can be improved by changing the ND of the ionomer. Furthermore, the degree of deformation of domains before and after elongation was examined. Figure 6(a) and 6(b) show TEM images of the TPEE/EMAA-54Na ionomer blend before and after elongation, respectively. The arrow in Figure 6(b) indicates the direction of elongation; dispersed domains were well deformed in the direction of uniaxial elongation. It should be noted that dispersed domains of the EMAA-Na ionomer, with higher viscosity than the TPEE matrix, are well elongated in TPEE matrix. Considering the change in morphology after uniaxial elongation, it is expected that the apparent strain hardening under uniaxial elongation shown in Figure 2 was due to the unexpected deformation of EMAA-Na domains in the TPEE matrix. However, the deformation of domains is easily accomplished, because the EMAA-Na domains are viscous and rigid compared to the TPEE matrix. Therefore, it should be noted that the deforma-

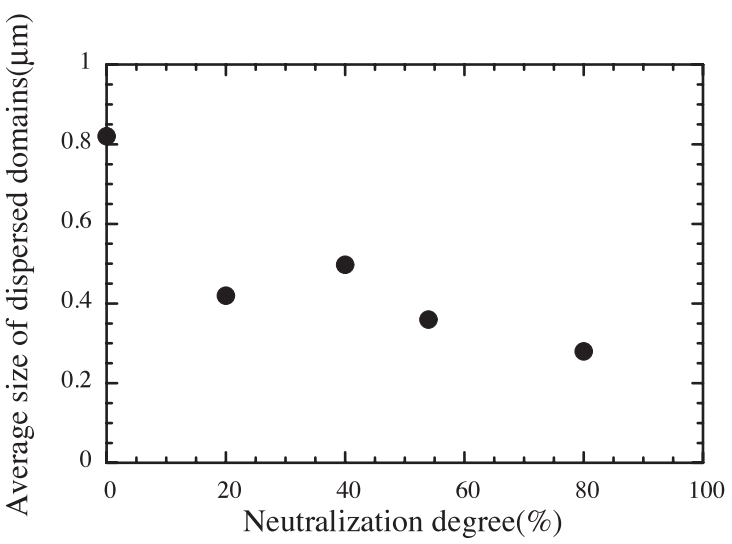

Figure 5. Average of diameter for dispersed domains obtained from Figure 4 as a function of the degree of neutralization (ND).

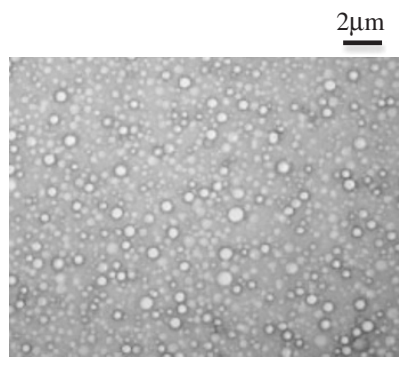

(a) Before elongation $(\varepsilon=0)$

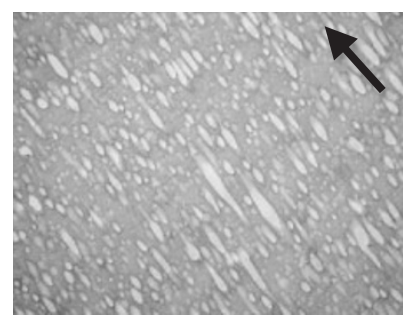

(b) After elongation ( $\varepsilon=2.0$ )
Figure 6. TEM images of TPEE/EMAA-54Na (a) before and (b) after elongation at $230^{\circ} \mathrm{C}$. The strain rate and Hencky strain $\varepsilon$ are $0.2 \mathrm{~s}^{-1}$ and 2.0, respectively. The arrow shown in Figure 6(b) indicates the direction of elongation.

tion of EMAA-Na ionomer domains after elongation and the increase in the intensity of strain hardening are unexpected. Similar results have been reported for significant strain hardening in the case of immiscible blend systems. da Silva et al. reported the effect of a compatibilizer on rheological properties such as uniaxial elongational viscosity for a polyethylene terephthalate (PET)/liquid crystalline polymer (LCP) blend system. ${ }^{25}$ They concluded that intensity of strain hardening for uniaxial elongational viscosity was affected by the degree of miscibility of the blended polymers. Minegishi et al. examined the effect of dispersed rigid domains on strain hardening under uniaxial elongation for a polystyrene (PS)/ styrene-butadiene-styrene (SBS) triblock copolymer blend system, ${ }^{26}$ and reported that the degree of deformation of dispersed domains significantly affected the intensity of strain hardening. For acrylonitrile-butadiene-styrene (ABS), Takahashi et al. reported the effect of hardness (degree of crosslinking) of butadiene on uniaxial elongational viscosity. ${ }^{27}$ ABS has a two-phase structure where butadiene particles grafted with acrylonitrile-styrene (AS) are dispersed in the AS matrix. They found that the deformation of a butadiene particle was sensitive to its hardness, which was controlled by the degree of crosslinking. Hard butadiene particles that were hardly deformed weakened the effect of strain-hardening. 
The reason for the apparent increase of strain hardening observed should be discussed for the present immiscible blend system. Considering the previously cited research, the contribution of miscibility between TPEE and the EMAA-Na ionomer on strain hardening should be examined. According to the average domain size shown in Figure 5, the interface interaction of the ionomer with a ND of $20 \%$ is no less than the interface interaction of that with a ND of $40 \%$. However, the ionomer with ND of $20 \%$ did not exhibit strain hardening in the blend. That is, strain hardening and high linear viscosity $\left(3 \eta_{\mathrm{s}}(t)\right)$ was observed only when ND $\geq 40 \%$.

Therefore, the apparent enhancement of strain hardening for TPEE after blending with the EMAA-Na ionomer can be explained by the acid-cation exchange mechanism in the ion aggregates, as proposed by Vanhoorne and Register. ${ }^{15}$ They studied the effect of acid group protons on the melt rheology of partially neutralized EMAA ionomer. Removal of the protons by etherification of the acid group revealed that the role of protons in the $\mathrm{Na}$ ionomers was different from that of $\mathrm{Zn}$ ionomers. ${ }^{15}$ In case of $\mathrm{Na}$ ionomers, a $\mathrm{Na}^{+}$ion is not only paired with a single $\mathrm{COO}^{-}$, but also interacts with two $\mathrm{COOH}$ acid groups by coordination bonds. Therefore, the $\mathrm{COOH}$ acid groups tend to be present around $\mathrm{Na}$ ions and protons can be exchanged between $\mathrm{COO}-\mathrm{Na}$ and $\mathrm{COOH}$. This acid-cation exchange mechanism for $\mathrm{Na}$ type ionomers is effective only when ionomers forms ion aggregates. Therefore, for the case of the TPEE/EMAA-Na ionomer blends, the strain hardening appeared above $40 \%$, which corresponds to critical ND for the formation of ion aggregates. ${ }^{8}$ Vanhoorne and Register reported that ion hopping time $(\tau)$ of EMAA-Na ionomer is below $100 \mathrm{~ms}$ from dynamic rheological measurement. ${ }^{15}$ The ion hopping time $(\tau)$ means time of reversible equilibrium of bond and dissociation. According to their report, critical strain rate obtained from $\tau$ mentioned above is inverse of $100 \mathrm{~ms}$ giving $10 \mathrm{~s}^{-1}$. Nishioka et al. have already reported that in case of low strain rates below critical strain rate (inverse of $\tau$ ), pseudo cross-linking by metal ion in ionomers can be acted as effective one. ${ }^{28}$ On the other hand, it means that equilibrium might go mostly toward dissociation above critical strain rate. Thus, above critical strain rate, ion bonding of ionomers is not effective. Considering these facts, our all measurements of uniaxial elongaitional viscosity were conducted below its critical strain rate (strain rates $<10 \mathrm{~s}^{-1}$ ). In this condition, interaction from acid-cation exchange mechanism between TPEE and the EMAA-Na ionomer was effective one and ionomer domains was deformed during elongation.

Here we discuss about deformation of ionomer domain and applied strain. The measured Hencky strain $\varepsilon(t)$ of time $\mathrm{t}$ is defined by

$$
\varepsilon(t)=\ln \mathrm{L}(t) / \mathrm{L}(0),
$$

where $\mathrm{L}(t)$ is the sample length along the elongation direction. For the case of uniaxial elongation, incompressible condition provides

$$
\mathrm{W}^{2}(t) \mathrm{L}(t)=\mathrm{W}^{2}(0) \mathrm{L}(0),
$$

where $\mathrm{W}(t)$ is the sample thickness. Eqs (1), (2) and condition $\mathrm{L}(0)=\mathrm{W}(0)$ provides

$$
\frac{\mathrm{L}(t)}{\mathrm{W}(t)}=e^{\frac{3}{2} \varepsilon} .
$$

We define aspect ratio $\alpha$ of the deformed ionomer domain by

$$
\alpha(t)=\mathrm{D}_{1}(t) / \mathrm{D}_{\mathrm{s}}(t),
$$

where $\mathrm{D}_{1}(t)$ is longer diameter of deformed domain of ionomer, and $\mathrm{D}_{\mathrm{s}}(t)$ shorter one. Denoting $\alpha$ in the limit of affine deformation by $\alpha_{\mathrm{A}}$, we have

$$
\alpha_{\mathrm{A}}(t)=\frac{\mathrm{L}(t)}{\mathrm{W}(t)}=e^{\frac{3}{2} \varepsilon} .
$$

Balance of stress provides

$$
\eta_{\mathrm{I}} \dot{\varepsilon}_{\mathrm{I}}=\eta_{\mathrm{E}} \dot{\varepsilon}_{\mathrm{E}}
$$

where $\eta$ is elongation viscosity and subscript $\mathrm{I}$ is for ionomer and $\mathrm{E}$ is for elastomer (TPEE). When eq (5) governs the system we have

$$
\varepsilon_{\mathrm{I}}=\frac{\eta_{\mathrm{E}}}{\eta_{\mathrm{I}}} \varepsilon_{\mathrm{E}}
$$

We consider that the measured Hencky strain satisfies

$$
\varepsilon_{\mathrm{E}} \cong \varepsilon
$$

because TPEE is dominant in quantity of the present composite. With eq (6) we have aspect ratio

$$
\alpha_{\mathrm{V}}(t)=e^{\frac{3 \eta_{\mathrm{E}}}{2 \eta_{\mathrm{I}}} \varepsilon}
$$

where $\alpha_{\mathrm{V}}$ is the aspect ratio determined by ratio of viscosities. Eq (8) shows that when viscosities of ionomer and TPEE are different, aspect ratio of ionomer domain is determined by the ratio of viscosities and Hencky strain.

For the present case of $\eta_{\mathrm{E}} / \eta_{\mathrm{I}}<0.1$ we see that $\alpha$ of Figure 6(b) satisfies

$$
\alpha_{\mathrm{V}}<1.35<\alpha<\alpha_{\mathrm{A}}=20,
$$

by setting $\varepsilon=2$. This indicates that force due to elongating TPEE molecule to the interface is important because the present $\alpha$ is apparently larger than $\alpha_{\mathrm{V}}$. We consider that such interfacial force between elongating TPEE and ionomer comes from interaction between ion bonding and unneutralized - $\mathrm{COOH}$ group of TPEE. As a result, unexpected strong strain hardening can be observed.

\section{CONCLUSION}

Investigation of the effects of EMAA-Na ionomers on the strain hardening properties of TPEE provided some new findings. The experimental results revealed unexpectedly significant strain hardening for a TPEE/EMAA-Na blend ratio of $80 / 20 \mathrm{wt} \%$. This unexpected behavior was due to the strong interaction between TPEE and EMAA-Na ionomers for $\mathrm{ND} \geq 40 \%$, which corresponds to the critical ND for the formation of ion aggregates. It was concluded that this strong 
interaction arises from acid-cation exchange mechanism between TPEE and the EMAA-Na ionomer. As a result, we have suggested a new application of EMAA-Na ionomers for improving the intensity of strain hardening for low melt strength material such as TPEE. It is considered that blending EMAA-Na ionomers with TPEE is one of the effective methods for modification of the intensity of strain hardening under uniaxial elongation.

Acknowledgment. We are grateful to Mitsui-DuPont Polychemicals Co., Ltd. and Toyobo Co., Ltd. for providing samples and for helpful discussions. The authors would also like to thank Prof. S. Ikeda, Dr. M. Nishio (Fujimori Kogyo Co., Ltd., Japan) and Mr. Keiji Katsuno for their valuable comments. This work was supported by Grants-in-Aid from the Ministry of Education, Culture, Sports, Science and Technology of Japan, No. 19710075.

Received: January 5, 2009

Accepted: May 3, 2009

Published: June 17, 2009

\section{REFERENCES}

1. A. Eisenberg, Macromolecules, 3, 147 (1970).

2. R. Longworth and D. J. Vaughan, Nature, 218, 85 (1968).

3. D. Yarusso and S. L. Cooper, Macromolecules, 16, 1871 (1983).

4. D. Yarusso and S. L. Cooper, Polymer, 16, 371 (1985).

5. W. J. Macknight, W. P. Taggart, and R. S. Stein, J. Polym. Sci., Polym. Symp., 45, 113 (1974).

6. T. Tachino, H. Hara, E. Hirasawa, S. Kutsumizu, K. Tadano, and S. Yano, Macromoecules, 26, 752 (1993).

7. E. Hirasawa, Y. Yamamoto, K. Tadano, and S. Yano, J. Appl. Polym. Sci., 42, 351 (1991).

8. A. Nishioka, M. Nishio, T. Koda, S. Ikeda, and K. Koyama, Nihon Reoroji Gakkaishi, 33, 201 (2005).

9. K. Sakamoto, W. J. MacKnight, and R. S. Porter, J. Polym. Sci.,
Part-2, 8, 277 (1970).

10. M. Nishio, A. Nishioka, T. Takahashi, J. Takimoto, and K. Koyama, Nihon Reoroji Gakkaishi, 30, 155 (2002).

11. A. Nishioka, T. Takahashi, Y. Masubuchi, J. Takimoto, and K. Koyama, Polymer, 42, 7907 (2001).

12. A. Nishioka, T. Takahashi, Y. Masubuchi, J. Takimoto, and K. Koyama, J. Rheol., 46, 1325 (2002).

13. T. Takahashi, J. Watanabe, K. Minagawa, and K. Koyama, Polymer, 35, 5722 (1994).

14. T. Takahashi, J. Watanabe, K. Minagawa, J. Takimoto, K. Iwakura, and K. Koyama, Rheol. Acta, 34, 163 (1995).

15. P. Vanhoorne and R. A. Register, Macromolecules, 29, 598 (1996).

16. J. Nazabal, A. Retolaza, and J. L. Eguiazabal, Polym. Eng. Sci., 42, 2072 (2002).

17. K. Hausmann, Kunststoffe, 83, 820 (1993).

18. K. Hausmann, Kunststoffe, 85, 446 (1995).

19. A. Nishioka, M. Nishio, M. Sugimoto, T. Takahashi, T. Koda, S. Ikeda, and K. Koyama, Nihon Reoroji Gakkaishi, 32, 49 (2004).

20. A. Nishioka, T. Koda, K. Miyata, G. Murasawa, and K. Koyama, Polym. J., 40, 350 (2008).

21. F. T. Trouton, Proc. R. Soc., A77, 426 (1906).

22. K. Koyama and O. Ishizuka, Nihon Reoroji Gakkaishi, 13, 93 (1985).

23. G. Z. Li, T. Matsuda, A. Nishioka, K. Miyata, Y. Masubuchi, K. Koyama, and C. U. Pittman, Jr., J. Appl. Polym. Sci., 96, 706 (2005).

24. G. Z. Li, T. Matsuda, A. Nishioka, K. W. Liang, Y. Masubuchi, K Koyama, and C. U. Pittman, J. Appl. Polym. Sci., 104, 352 (2007).

25. L. B. da Silva, M. M. Ueki, M. Farah, and R. E. S. Bretas, Rheol. Acta, 45, 268 (2006).

26. A. Minegishi, A. Nishioka, A. Minegishi, T. Takahashi, T. Koda, Y. Masubuchi, J. Takimoto, and K. Koyama, Nihon Reoroji Gakkaishi, 33, 14 (2005).

27. T. Takahashi, W. Wo, H. Toda, J. Takimoto, T. Akatsuka, and K. Koyama, J. Non-Newtonian Fluid Mech., 68, 259 (1997).

28. A. Nishioka, T. Takahashi, Y. Masubuchi, J. Takimoto, and K. Koyama, J. Rheol., 46, 1325 (2002).

29. J. Meissner, Rheol. Acta, 8, 78 (1969).

30. M. Nishio, A. Nishioka, T. Taniguchi, and K. Koyama, Polymer, 46, 261 (2005).

31. H. Tachino, E. Hirasawa, S. Kutsumizu, and S. Yamamoto, Macromolecules, 27, 372 (1994). 